\begin{tabular}{|l|l|}
\hline Quick Response Code: & Website: \\
www.annalsafrmed.org \\
\hline
\end{tabular}

\title{
Severe pentasomide Armillifer armillatus infestation complicated by hepatic encephalopathy
}

\author{
Ademola A. Adeyekun, Ikechukwu Ukadike, Victor A. Adetiloye ${ }^{1}$ \\ Department of Radiology, University of Benin Teaching Hospital, PMB 1111 Benin City, ${ }^{1}$ Department of \\ Radiodiagnosis, Obafemi Awolowo University Teaching Hospital PMB 1153 Ile-Ife, Nigeria
}

Correspondence to: Dr. Ademola A. Adeyekun, Department of Radiology, University of Benin Teaching Hospital, PMB 1111 Benin City, Nigeria. E-mail: adeyekun@yahoo.com

\begin{abstract}
Background: Diagnosis of Armillifer armillatus infestation is usually incidental, commonly via autopsy or radiography. Affected individual are usually asymptomatic. The case presented here, however, had severe thoracic and abdominal involvement with clinical manifestations.

Aim: To report a case of heavy A. armillatus infestation in an adult female Nigerian rural dweller complicated by hepatic parenchyma damage.

Setting: Case report from semi-urban southern Nigeria, using clinical records and imaging findings. Materials and Methods: Clinical case records, including laboratory results and radiographic/computed tomography images.

Conclusion: Parenchymal damage with organ dysfunction can be seen with severe A. armillatus infestation. Thus, there is a need for regular health education regarding the risk of $A$. armillatus infestation for individuals who consume snake meat.
\end{abstract}

Keywords: Armillifer armillatus, hepatic encephalopathy, snake meat consumption

\section{Résumé}

Fond: Diagnostic de Armillifer armillatus infestation est généralement accessoire, généralement via l'autopsie ou de radiographie. Personne sont habituellement asymptomatique. Le cas présenté ici, cependant, avaient atteinte grave, thoracique et abdominal, avec les manifestations cliniques.

But: Pour signaler un cas de lourds, une infestation d'armillatus dans un océan rural nigérian femelle adulte compliquée par le parenchyme hépatique dommages.

Paramètre: Rapport de la cas de semi-urbaines sud du Nigeria, à l'aide de dossiers cliniques et l'imagerie des conclusions.

Méthodes et matériaux: Dossiers cliniques, y compris les résultats de laboratoire et des images de tomographie radiographique / calculée.

Conclusion: Parenchymal dommages avec un dysfonctionnement organique peuvent être vus avec grave une infestation d'armillatus. Ainsi, il est nécessaire pour l'éducation en santé régulières concernant le risque d'une infestation d'armillatus pour les personnes qui consomment de la viande de serpent.

Mots clés: Armillifer armillatus, encéphalopathie

hépatique, la consommation de viande de serpent

\section{Introduction}

Armillifer armillatus is a type of worm belonging to the phylum Pentastomida. Pentastomiasis, also known 
as porocephalosis or tongue worm infestation, is a rare infection that is generally limited to the tropics and subtropics. The worm normally inhabits the respiratory tract of snakes and reptiles and only occasionally infects humans.

The radiological literature on pentastomiasis is sparse. Linguatula serrata and $A$. armillatus account for more than $99 \%$ of all reported human cases. ${ }^{[1]}$ When the parasite load is low, the overwhelming majority of cases are asymptomatic and are generally discovered only incidentally during autopsy, routine $\mathrm{x}$-ray examination, or surgery.

A case of heavy $A$. armillatus infestation with derangement of hepatic function is presented in this article; we report this case because of the unusual presentation.

\section{Case Report}

A 57-year-old farmer, was referred to the medical outpatient department with a 6-month history of mood disturbance, occasional confusional state, depression, pruritus, and altered sleep pattern. The pruritus was more pronounced at night. Her past medical history revealed that she had been treated on several occasions for pneumonia. About $2 \frac{1}{2}$ years earlier she had been treated for pulmonary tuberculosis at a peripheral hospital. She had had several episodes of upper abdominal pain associated with vomiting and the passage of watery stool, but these attacks had all been managed conservatively. There was no previous history of blood transfusion or regular usage of sharp objects like piercing needles. There was associated weight loss.

On examination, she looked chronically ill and was emaciated. She was pale and mildly icteric, but was not dehydrated. There was finger clubbing. The other positive findings included a musty breath odor, mild flapping tremor (mild asterixis), and features of muscle rigidity. The chest, abdominal, and cardiovascular examinations were all normal. Her blood pressure was 130/90 and her pulse rate was 92 beats per minute. A working diagnosis of possible grade 1 hepatic encephalopathy, secondary to chronic liver disease, was made and radiological and laboratory investigations were requested.

Among the laboratory investigations, liver function test revealed increased alkaline phosphatase (ALP) of $55 \mathrm{U} / 1$ (normal 5-35 U/1). The enzymes GGT and 5 -nucleotidase were not assayed because of lack of facilities. The serum total bilirubin was $2.3 \mathrm{mg} / \mathrm{dl}$ (normal $0.5-1.5 \mathrm{mg} / \mathrm{dl}$ ) and conjugated bilirubin was $1.2 \mathrm{mg} / \mathrm{dl}$ (normal $<0.05 \mathrm{mg} / \mathrm{dl}$ ). The serum total protein was low at $5.0 \mathrm{mg} / \mathrm{dl}$ (normal range $5.5-6.9 \mathrm{mg} / \mathrm{dl}$ ), albumin was low at $2.2 \mathrm{mg} /$ $\mathrm{dl}$ (normal 3.5-5.0 mg/dl). The urea level was 6.1 $\mathrm{mg} / \mathrm{dl}$ (normal 10-50 mg/dl). The hemoglobin level was low $(9.2 \mathrm{~g} / \mathrm{dl})$. Hepatitis B surface antigen (HbsAg) was negative. She did not give consent for liver biopsy.

Chest x-ray revealed multiple crescentic, commashaped, calcific opacities distributed in both hemithoraces [Figure 1], with marked concentration of these opacities in the right hemidiaphragmatic region. A diagnosis of $A$. armillatus parasitic infestation was made based on the typical shape of the opacities. On further questioning, the patient confirmed that snake meat had been a regular part of her diet for many years and that she always prepared the meat herself.

A thoraco abdominal CT scan was done subsequently. The scanogram showed multiple crescentic, commashaped, calcific densities distributed over the entire

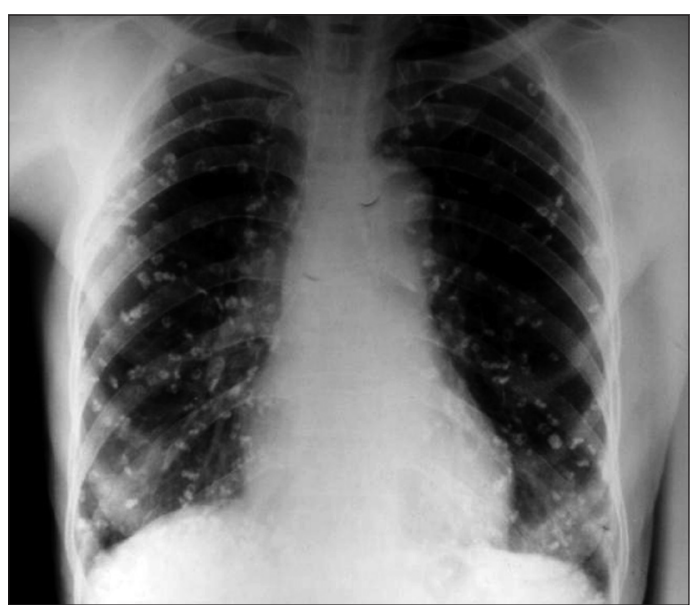

Figure 1: Posteroanterior chest radiograph with bilateral, multiple, crescentic calcific densities of dead armillifer larvae.

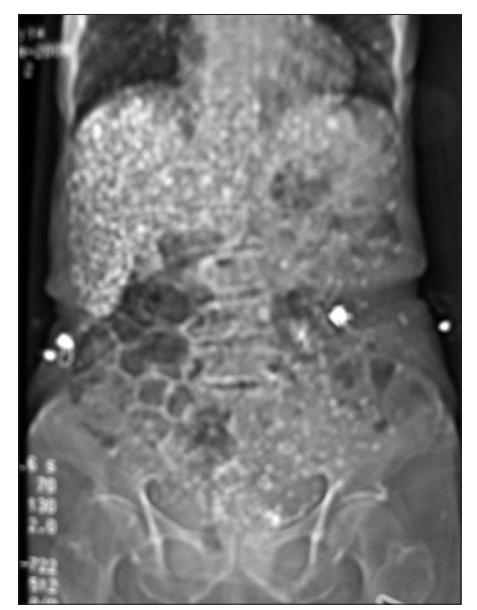

Figure 2: Abdominal CT-scannogram showing the numerous crescentic calcific densities, especially over the hepatic region. 
abdomen, with predominance in the hepatic region [Figure 2]. Transverse non-enhanced slices showed overwhelming hepatic involvement by the calcific deposits, with gross distortion of the liver parenchyma [Figure 3]. The deposits were also concentrated in the spleen. The bowels, mesentery, and the urinary bladder were also affected [Figure 4]. A radiologic diagnosis of severe $A$. armillatus infestation with liver parenchyma involvement was made.

She was managed as a case of grade 1 hepatic encephalopathy secondary to severe liver parenchymal parasitic infestation. She was placed on a high-carbohydrate, low-protein diet and treated with antibiotic (metronidazole), antihistamines, and lactulose.

On follow-up 3 weeks later at the outpatient clinic she showed significant clinical improvment.

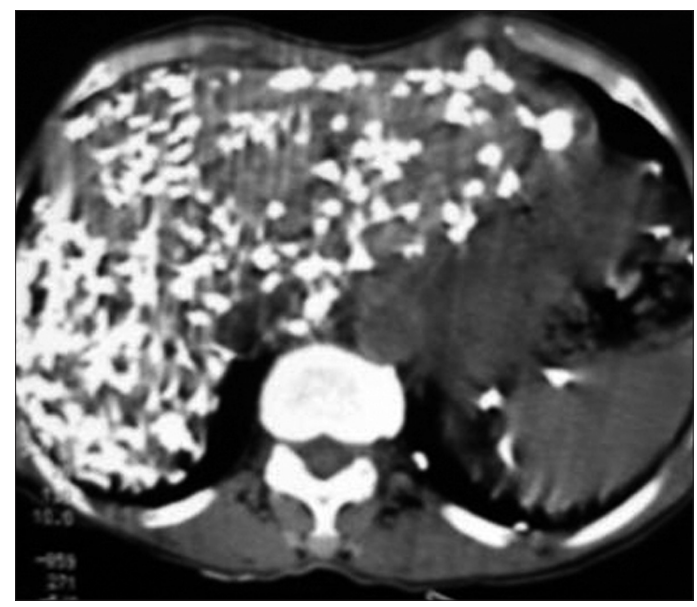

Figure 3: Non-enhanced axial CT-slice of the upper abdomen showing concentration of the calcific deposits in the liver, with parenchymal distortion.

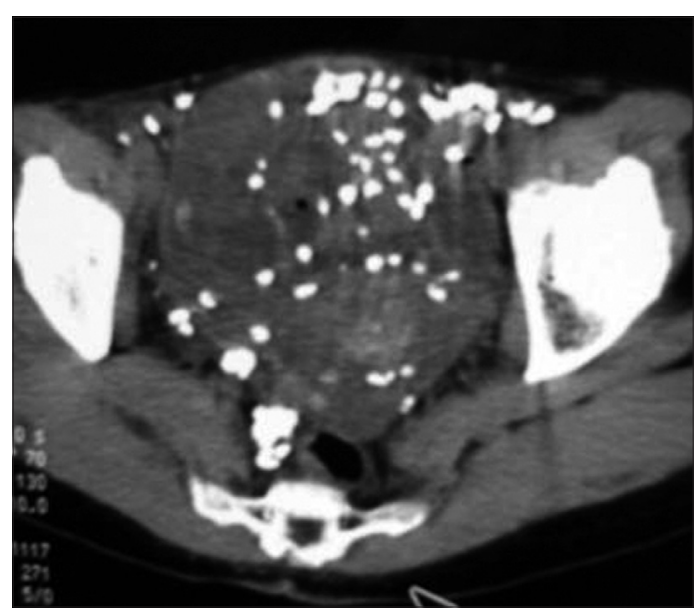

Figure 4: Non-enhanced axial CT-slice of the pelvis showing the crescentic calcific deposits over the bowel (including rectum), mesentery and the urinary bladder.

\section{Discussion}

The first human infection by a pentastomid was described by Prunner in Cairo in 1847..$^{[2]}$ Two species, A. armillatus and Linguatula serrata, account for more than $99 \%$ of all reported human cases. ${ }^{[1]}$ Among the four species of Armillifer, armillatus is found most commonly in West Africa, where the infection rate may be as high as $23 \%$ and the radiological incidence about $1.4 \% .{ }^{[3]}$ Infestation by $A$. armillatus was diagnosed radiologically in this woman. The other species of Armillifer which can also be recognized radiologically is $A$. monniliformis, which causes porocephalosis. It is not common in West Africa but is found in South and East Asia. Prathap et al. found a $45 \%$ incidence during autopsies in Malaysian aborigines. ${ }^{[4]}$ This disease is commoner in males than in females as documented by Nzeh $e t$ al. ${ }^{[5]}$ with a male: female ratio of $2: 1$. Our patient too was a female.

Infection with pentastomids is mostly asymptomatic in humans, being especially seen in those who regularly consume snake meat. Our patient admitted to having regularly eaten snake meat for several years. The larvae usually die and calcify within 2 years of infection of a human host. ${ }^{[6]}$ However, pentastomids have the potential to cause harm, and, in rare cases, even to cause medical emergencies. ${ }^{[7]}$ In heavy infestation, as in this case, the migration of many live larvae beneath the peritoneum or pleura may cause sufficient irritation to mimic an acute abdominal condition or pleurisy. ${ }^{[7]}$ The encysted larvae can cause abdominal pain, vomiting, constipation, and diarrhea. The presence of extremely high numbers of cysts in some locations can even cause death. ${ }^{[8]}$ Pneumonitis, bronchitis, pleuritis, pericarditis, hepatitis, and peritonitis, have all been noted in patients with severe infection..$^{[3]}$ Our patient, according to her past medical history, had been treated several times for pneumonitis and abdominal discomfort; it is likely that the heavy infestation was responsible for those illnesses. She had also been treated for primary pulmonary tuberculosis and this too may have been a misdiagnosis of the pneumonitis and granulomas caused by the worm infestation.

Our patient presented with features of grade 1 hepatic encephalopathy, which was likely the result of extensive hepatic parenchymal destruction due to severe granulomatous reaction. A study in Ibadan, Nigeria, by Smith et al. ${ }^{[8]}$ found pentastomiasis to be the third most common cause of hepatic fibrosis after tuberculosis and schistosomiasis. This form of presentation may be as a result of the accumulation of neurotoxic substances that would 
normally have been metabolized by the liver. Our patient also had mild jaundice which, from the laboratory investigations, was obstructive in nature. This may also be as a result of fibrosis around the porta hepatis due to the extensive granulomatous reaction. Liver biopsy could have confirmed the diagnosis but was not done because patient did not consent to the procedure.

Page $\mid 62$

The diagnosis of pentastomiasis is mostly made incidentally at surgery, at autopsy or during radiographic examinations. The serological test for Armillifer is rarely used in clinical practice ${ }^{[9]}$ and is often not available. Hence, it was not done in this patient. Laboratory investigations for this woman revealed elevated ALP and total bilirubin, which was suggestive of cholestasis. Her clinical presentation and response to therapy supported the diagnosis of hepatic encephalopathy.

Because pentastomiasis is mostly asymptomatic, it is often detected during radiological examination for other conditions. The diagnosis in our patient was made when chest radiography was done as part of her workup at admission to the hospital. The calcified dead larvae of armillifer are almost always localized to the abdomen and chest and are rarely seen at other sites, as demonstrated in this case. They are always multiple and are most commonly seen in the liver but can also involve the intestinal walls, peritoneum, mesentery, and lungs. ${ }^{[3,9]}$ The liver in this woman had the highest concentration but almost all the intra-abdominal structures were affected. The calcifications are described as crescentic, horseshoe, or commashaped. ${ }^{[3,10]}$ This pattern of calcification was noted in our patient also.

CT scan was helpful in the radiological investigation of this patient. The gross hepatic parenchymal distortion was well delineated. Also, it helped to outline the calcific crescentic deposits in almost all the intra-abdominal structures.
Treatment of this larval pentastomiasis is usually conservative, as the majority of the cases are asymptomatic. Antibiotics or surgical therapy is rarely needed. Our patient was also managed conservatively.

\section{Conclusion}

A case of heavy infestation of $A$. armillatus, with significant pulmonary and hepatic involvement is presented in this article. Health education should discourage the consumption of snake meat and arthropods.

\section{References}

1. Cannon DA. Linguatid Infestation of Man. Ann Trop Med 1942;36:160-7.

2. Hopps HC, Howard C. Pentastomiasis. In: MarcialRojas RA, editor. Pathology of Protozoal and Helminthic Diseases. Baltimore: Williams and Wilkins; 1971. p. 970-989.

3. Reeder MM, Palmer PES. The Imaging of Tropical Diseases with Epidemiological, Pathological and Clinical Correlation. Baltimore: Williams and Wilkins; 1981. P. 389-95.

4. Prathap K, Lau KS, Bolton JM. Pentastomiasis: A common finding at autopsy in Malaysian aborigines. Am JTrop Med Hyg 1969;18:20-27.

5. Nzeh DA, Akinlemibola JK, Nzeh GC. Incidence of Armillifer aarmillatus (pentastome) calcification in the abdomen. Cent Afr ] Med 1996;42:29-31.

6. Drabick J]. Pentastomiasis. Rev Infect Dis 1987;9:108794.

7. Herzog U, Marty P, Zak F. Pentastomiasis: Case report of an acute abdominal emergency. Acta Tropica 1985;42:261-71.

8. Smith JA, Oladiran B, Lagundoye SB. Pentastomiasis and malignancy. Ann Trop Med Parasitol 1975;69:503-12.

9. Pieron R, Mafart Y, Lesobre B, Meyniel D. Two cases of Pentastomiasis observed in Paris. Semaine des Hopitaux 1982;58:1047-48.

10. Ancelle T, Daireaux P, Chemoul F, Lapierre J. A case of porocephalosis disclosed by echography during evaluation of hepatic amebiasis. Presse Med 1988;17:437.

Source of Support: Nil, Conflict of Interest: None declared. 